\title{
ANÁLISE DO DISCURSO E LITERATURA: UM DIÁLOGO POSSÍVEL NO ROMANCE O DIA EM QUE MATEI MEU PAI, DE MARIO SABINO
}

\author{
CEZAR ROBERTO VERSA ${ }^{1}$ \\ ALEXANDRE SEBASTIÃO FERRARI SOARES ${ }^{2}$
}

UNIOESTE - Universidade Estadual do Oeste do Paraná

R. Universitária, 2069 - 85819-110 - Jardim Universitário, Cascavel - PR

$\underline{\text { cezarversa@hotmail.com ; asferraris@globo.com }}$

\begin{abstract}
Resumo. A interface teórica constitui a Análise do Discurso de linha francesa (AD), por meio de teorias como a linguística, o materialismo histórico e a psicanálise. Ao destituir o caráter da intencionalidade, produz um distanciamento em relação a obras artísticas, as quais se demarcam na subjetividade. O presente artigo traz como problema de pesquisa essa situação conflituosa ao propor uma análise de um texto literário por meio da AD. Toma-se como corpus a obra $O$ dia em que matei meu pai, de Mario Sabino, um romance cuja inscrição de efeitos de sentido se estabelece no nível de um discurso psicanalítico. A partir de uma Sequência Discursiva, demonstram-se os efeitos de sentido advindos de formações ideológicas e discursivas de vários níveis: do senso comum, do religioso e do científico.
\end{abstract}

Palavras-chave: Análise do Discurso; literatura; efeitos de sentido; psicanálise; parricídio.

\begin{abstract}
The theoretical interface constitutes the Discourse Analysis, of French Line (AD), through theories such as linguistics, historical materialism and psychoanalysis. By removing the character of intentionality, it produces a distance from artistic works, which are demarcated in subjectivity. This paper presents as a research problem this conflicting situation when proposing an analysis of a literary text through AD. It takes as a corpus the book The day I killed my father, by Mario Sabino, a novel whose inscription of meaning effects is established at the level of a psychoanalytic discourse. From a Discursive Sequence we demonstrate the effects of sense coming from Ideological and Discursive Formations of several discursive levels: of the common sense, the religious and the scientific.
\end{abstract}

Keywords: Discourse Analyses; literature; meaning effects; psychoanalysis; parricide.

\footnotetext{
${ }^{1}$ Doutor em Letras pela Universidade Estadual do Oeste do Paraná; docente da UNIVEL (Faculdade de Ciências Sociais Aplicadas de Cascavel) e do Colégio Marista de Cascavel.

${ }^{2}$ Vice-coordenador do Programa de Pós-Graduação em Letras da UNIOESTE.
} 


\section{INTRODUÇÃO}

O conhecimento é uma instância legitimadora de saberes, em que as construções conceituais se efetivam tanto na corroboração quanto na quebra de paradigmas. Nesse sentido, a presente discussão se delimita num processo de rompimento paradigmático, ao se propor a composição de um artigo em que a Análise do Discurso de linha francesa, doravante $\mathrm{AD}$, é aplicada em um texto literário. O corpus analítico é um romance contemporâneo de Mario Sabino, intitulado $O$ dia em que matei meu pai. Para fins metodológicos e processuais, tomaremos uma Sequência Discursiva (SD), em específico, para a composição analítica.

Por mais que a literatura trabalhe com o ficcional, as condições de produção de um discurso podem sim ser pensadas, quando destituímos o caráter da autoria, vista esta numa acepção de subjetividade cara ao Romantismo, como destacada por Possenti (2009). Contudo, apenas esse argumento não traria à baila o porquê de se pensar a possibilidade de uma análise do discurso dentro de um texto literário. Nesse ponto, reside a importância de destacarmos os motivos da obra $O$ dia em que matei meu pai ter nos levado a esse campo teórico e analítico da AD.

O título, bem sugestivo quanto ao caráter edipiano, fortaleceu-se quando o processo do relato de alguém na posição de sujeito-louco, o protagonista da obra, começou a estabelecer relações com o discurso psicanalítico e com a teoria do discurso jurídico da forma sujeito de direito, tão cara aos estudos de linha marxista de entendimento quanto ao Estado dito moderno. Isto é, diante de nós despontou a possibilidade de analisarmos discursos transversos e fundantes da própria $\mathrm{AD}$, quando pensamos na psicanálise lacaniana e nos estudos de Althusser, dentro de uma acepção materialista dialética.

O efeito de sentido do discurso psicótico é o fio analítico a ser seguido, deslocando suas composições em variadas Formações Discursivas (FD), como as do discurso da racionalidade e da logicidade, nas perspectivas cartesiana, iluminista e positivista; do discurso religioso, baseadas nos valores morais do cristianismo; do discurso científico presente nas FD do direito e da medicina, na diferenciação de crime e medida de segurança e na validação de laudos de demência.

\section{ANÁLISE DO DISCURSO, BREVE DESVELAR TEÓRICO E CONCEITUAL}

A Análise do Discurso de linha francesa advém de questionamentos da própria significação do conhecimento científico em relação à linguagem. Ao fazê-lo coincidiram sobre sua origem, arcabouços teóricos distintos e até então incomunicáveis, como o materialismo histórico e a psicanálise.

Cabe destacar, que a $\mathrm{AD}$ surgiu no contexto de uma linguística estrutural, já que na França, nos anos de 1960, havia uma tradição de se estudar o texto por meio de reflexões acerca da história. Nos anos de 1970, no cenário da linguística francesa, havia o entendimento de que a análise de discurso se perfaria como uma saída para repensar a 
própria ciência da linguagem, por meio da inserção de conceitos como a ideologia, o sujeito e o discurso.

A gênese da AD se estabeleceu em dois nomes: Jean Dubois e Michel Pêcheux, os quais foram influenciados pelo distribucionalismo de Harris, que trazia uma abordagem da escola americana estruturalista. Harris trabalha a partir do sintagma "análise do discurso", descartava a questão do sujeito e rejeitava a questão do sentido fora da linguística (MAZIÈRE, 2007).

Por um encontro singular, no qual é difícil não ver um efeito da conjuntura, no momento em que Michel Pêcheux colocava sua análise automática do discurso, o lingüista Jean Dubois abria pesquisas interdisciplinares em torno do discurso político. Logo a análise de discurso designava o objeto dessa dupla fundação. (MALDIDIER, 2003, p. 36)

Dubois era um linguista e lexicólogo já consagrado e Pêcheux, um filósofo que pautava seus estudos nos questionamentos da história das ciências que, por mais diferentes que fossem suas ambiências de atuações, acabavam por atuar em um espaço comum: a política e o marxismo.

Em Dubois, a AD possibilitaria a transição de um estudo do léxico para o do discurso, baseado este nos enunciados, por uma transposição natural. De acordo com Mazière (2007, p. 31), "Por meio de um verdadeiro golpe de força, ao transportar para a linguística estrutural o objeto discurso, Dubois vai possibilitar a abertura de uma nova região na disciplina 'linguística'”.

Já em Pêcheux, "ao contrário, a análise de discurso é pensada como uma ruptura epistemológica em relação ao que se fazia nas ciências humanas, articulando a questão do discurso com as do sujeito e da ideologia" (BRANDÃO, 2003, p. 5).

Maldidier (2003) assevera que é em Pêcheux que ocorre a demarcação dos conceitos utilizados seja por linguistas ou historiadores marxistas para a análise de discursos. Uma série de rupturas quanto ao entendimento da articulação da língua, ideologia e discurso se processaram dando os contornos futuros à teoria.

As maiores quebras, em relação à linguística, perfizeram-se à dicotomia langue e parole, de Saussure, pois o discurso não encerraria seu posicionamento nem em um nem outro processo dessa dualidade conceitual. Mesmo as questões da diacronia e da sincronia, não dariam conta do processo de formações ideológicas e discursivas acontecidas em determinado momento histórico por um determinado sujeito que se entendia centralizador, mas que não tinha noção de seu assujeitamento frente aos momentos vividos.

A AD é considerada, assim, uma teoria de ruptura, o resultado de uma série de reflexões filosóficas e epistemológicas, construídas a partir de críticas ao realismo metafísico platônico e do empirismo lógico aristotélico, cujas representações de sentido se efetivam na dualidade lógica e retórica, em que a primeira ressoa em relação à segunda. O materialismo foi a alternativa viável para a saída dos idealismos tanto de Platão quanto de Aristóteles, atrelado ainda aos estudos da psicanálise. 
É necessário destacar que a cientificidade da $\mathrm{AD}$ tem seu vínculo à linguística, e que a formação de sua comutação teórica se efetiva via materialismo althusseriano e a psicanálise lacaniana. Possenti $(2005$, p. 357$)$ destaca que "A AD pode tratar cada um desses 'temas' - mas os trará rompendo com o que a linguística faz com cada um deles".

Em relação às teorias filosóficas idealistas, o ideário de que a consciência cria a existência se torna o ponto de contradição aos entendimentos da $\mathrm{AD}$, pois o sujeito teria em si a aura de criação, é ele que sabe, cria, domina os objetos. No cruzamento teórico das bases da $\mathrm{AD}$, pode-se perceber que o sujeito detentor de sentidos é desconstruído.

São três regiões do conhecimento que apontam para essa reconfiguração: o marxismo, que afirma a não transparência da história, a psicanálise, que "escuta" a não-transparência do sujeito, e a linguística, que se constitui na não transparência da língua. $\mathrm{O}$ que acarreta imediatamente dois deslocamentos paralelos: o do sentido e o da própria língua, posta essa relação com a história. A Análise do Discurso é a forma de conhecimento que se realiza em seu objeto - o discurso - pela conjunção desses três modos de opacidade: a do sujeito, a da língua e a da história. (ORLANDI, 2002, p. 65)

Por isso, um dos principais cismas da AD é a desconstrução de um sujeito que tenha domínio sobre o sentido e a língua deixa de ser vista como algo transparente, já que as condições de produção do que é dito desloca os próprios sentidos do dito e do não dito. Logo, a língua não é transparente, nem o sujeito é exterior a ela.

O 'desdobramento' do sujeito - como 'tomada de consciência' de seus 'objetos' - é uma reduplicação da identificação, precisamente na medida em que ele designa o engodo dessa impossível construção da exterioridade no próprio interior do sujeito. (PÊCHEUX, 1997, p. 172)

Discursivamente, é no sujeito que a língua acontece no homem, o qual não se destitui de suas ideologias nem de seu inconsciente. Sendo que ocorre, na clivagem do inconsciente e na interpelação ideológica do indivíduo, a constituição de um sujeito assujeitado e demarcado pelos deslizes de sentido construídos em seus discursos.

Faz-se mister destacar que não se pretende por meio da $\mathrm{AD}$ polarizar uma relação entre língua e discurso, como na relação dicotômica de Langue e Parole, de Saussure. Na acepção estruturalista, a língua era entendida dentro de um sistema fechado em si mesmo, não pensada sua relação como o mundo.

Saussure (2006) apresentava a língua como algo do social e exterior aos indivíduos, e a fala seu processo de ocorrência. A língua seria uma instituição social distinta, vista numa perspectiva separada de outras instituições como da política e da jurídica, por exemplo. A língua era vista no nível social e a fala no nível individual. Para Pêcheux (1993, p. 71), residia nesse ponto a homogeneização de seu estatuto científico.

Assim a língua é pensada por Saussure como um objeto científico homogêneo (pertencente à região do "semiológico"), cuja especificidade se estabelece sobre duas exclusões teóricas:

- a exclusão da fala no inacessível da ciência lingüística; 
- a exclusão das instituições "não-semiológicas" para fora da zona de pertinência da ciência linguística. (PÊCHEUX, 1993, p. 71)

Essa forma de entender a relação língua e fala, sob a ótica de Pêcheux (1993), resultou no triunfo da ideia de um sujeito falante, que traz sua subjetividade em ato, o qual parece declarar sua autonomia quanto às intenções. A língua tornou-se, na perspectiva da linguística estrutural científica, um caminho da liberdade humana, em relação à subjetividade.

Já para a $\mathrm{AD}$, é na língua que se constitui um processo de não-transparência, de uma opacidade, a qual desloca os sentidos e entra em interfaces e ruptura constantes com a história e com o sujeito, os quais também se operam num movimento de nãotransparência (ORLANDI, 2002). A língua não se torna uma estrutura apenas, mas também um acontecimento demarcado por uma série de condições de produção.

É nesse espaço que o discurso se efetiva, na plasticidade da língua quanto aos deslizes de sentido. As ideologias materializam-se nos discursos, de tal modo que o próprio discurso se materializa na língua. "todo enunciado é intrinsecamente suscetível de tornar-se outro, diferente de si mesmo, se deslocar discursivamente de seu sentido para derivar para um outro" (PÊCHEUX, 2008, p. 53).

Essa relação do outro constitutivo dos sentidos estabelece uma interface teórica entre a $\mathrm{AD}$ e a teoria lacaniana. Também se perfaz na interpelação ideológica, vinda de processos históricos do assujeitamento. Há sempre um outro, advindo do inconsciente, por meio do discurso: "Freud chamou aquele Outro lugar de inconsciente, e Lacan afirma em termos categóricos que 'o inconsciente é o discurso do outro', isto é, o inconsciente consiste naquelas palavras que surgem de algum outro lugar que não a fala do eu" (FINK, 1998, p. 20). Para os pressupostos da AD, esse eu consciente não é possível, devido ao seu assujeitamento. Esse sujeito acaba por se clivar na sua própria representação, por meio da linguagem, em que Lacan destaca ao compor o inconsciente como o discurso do outro, fato significativo a Pêcheux (1997).

Por isso, a estrutura da língua e seu acontecimento demarcam o discurso como objeto analítico. Os efeitos de sentido possibilitados no contexto de produção se estabelecem numa flutuação de significações, as quais dependerão dos modos de interpelação ideológica e da leitura interpretativa dos atos falhos do inconsciente por meio da linguagem.

\section{LITERATURA (EM)CENA DISCURSIVA}

Na gênese das aplicações de uma teoria da AD como instrumento analítico, alguns tipos de discursos apareceram como objeto de forma mais reiterada. $\mathrm{O}$ discurso político foi uma constante, pois os atravessamentos ideológicos possíveis de serem percebidos eram os mais variados. Outra ênfase, ainda uma muito forte na atualidade, diz respeito aos discursos midiáticos, isto é, o texto jornalístico apresenta-se como um objeto muito singular, pois é atravessado por ideologias e tem em suas condições de produção caracteres políticos. 
Orlandi (2004), por sua vez, pesquisadora da AD no Brasil, buscou em outros discursos, como o presente na arquitetura urbana, os efeitos de sentido que podem ser extrapolados nesse contexto. Onde for possível estabelecer linguagem será possível ler as formações ideológicas e discursivas presentes, por isso, a $\mathrm{AD}$ se abre como um dispositivo analítico e teórico com variadas possibilidades de aplicação.

A relação dos sentidos com a interpretação é um processo constante, já que não haveria sentido sem a interpretação e de que esta dependerá do ponto de vista de quem interpreta, em que sujeitos de linguagem e analistas muitas vezes divergem quanto ao sentido. Logo, a finalidade da análise do discurso não na interpretação, mas sim no processo de compreensão do funcionamento textual, de como um texto produz sentidos (ORLANDI, 2004).

Ressalta-se que o corpus da AD é o texto, entendido não numa leitura textual, mas sim, numa leitura discursiva, quanto as suas condições de produção. As palavras são interpretadas dentro de FD e dos processos de interpelação sofridos pelos sujeitos.

Nesta direção, penso, pode-se defender a ideia de que o árbitro definitivo da leitura é o texto, desde que o texto seja concebido discursivamente, ou seja, seja tomado como submetido a todas as restrições históricas que normalmente o afetam, e que afetam, portanto, seu autor e seu(s) leitor(es), submetendo-os tanto às regras de circulação quanto de interpretação .(POSSENTI, 2009, p. 19)

Destarte, a opacidade da língua, o assujeitamento dos sujeitos interpelados por ideologias e clivados em consciente e inconsciente possibilita a análise do texto enquanto estrutura (questão linguística) e acontecimento (questões ideológicas e do nível do inconsciente).

A literatura, pensada como um texto subjetivo, de composição intencional, como entende a pragmática, não poderia ser um objeto cabível à $\mathrm{AD}$. Contudo, quando falamos em discurso literário, podemos pensá-lo sob determinadas condições de produção. Ademais, há aquilo que foge dessa intenção do autor, os efeitos de sentido, o inconsciente que fala através da literatura. Possenti (2009) ressalta na questão do desvelamento institucional uma tendência dentro de uma análise do discurso em textos ditos subjetivos, como é o caso do discurso literário.

Fernandes (2009) destaca que a análise do discurso pode ser feita no texto literário se pensado as personagens como sujeitos discursivos. "[...] mesmo em produções literárias que trazem marcas de passionalidade, ou versam sobre sentimentalismo, a subjetividade é histórica e exteriormente modificada" (FERNANDES, 2009, p. 13).

Possenti (2009) destaca a AD como uma das melhores estratégias de leitura e que no texto tradicionalmente visto como subjetivo é possível compor um projeto de revelar seus critérios institucionais. Por isso, é possível tomar essa obra literária em seu nível discursivo, centrado nesse artigo em uma SD determinada. 


\section{NO MEIO DO CAMINHO: O DISCURSO DO CINZA}

Para perceber os efeitos de sentido perante essas composições analíticas, usaremos uma Sequência Discursiva (doravante SD). Entendemos a SD como o espaço de materialização discursiva, em que os sentidos se estabelecem num jogo intradiscursivo e interdiscursivo. Tomamos o texto, em sua materialidade linguística, o corpus de referência analítica. O discurso é visto como estrutura e acontecimento, não se adentrando em caracteres de análise literária:

todo enunciado, toda sequência de enunciados é, pois, linguisticamente descritível como uma série (léxico-sintaticamente determinada) de pontos de deriva possíveis, oferecendo lugar a interpretação. É nesse espaço que pretende trabalhar a análise do discurso. (PÊCHEUX, 2008, p. 53)

O discurso será analisado por meio de sua materialidade linguística, uma vez que a língua é opaca, materializa-se e apresenta as clivagens do sujeito que se entende como dono dos sentidos. Para tanto, esse indivíduo será entendido em seu processo de interpelação ideológica, tornando um sujeito assujeitado a condições de produções demarcadas no discurso e dentro de cada Formação Discursiva (doravante FD). Por FD, entendamos "aquilo que numa formação ideológica dada, isto é, determinada pelo estado da luta de classes, determina o que pode e deve ser dito" (PÊCHEUX, 1997, p. 160).

Por meio de Formações Ideológicas (doravante FI) é que se estabelecem o sentido das palavras a partir de um jogo de posições ideológicas. Nessa conceituação, a transparência da linguagem é revista, já que as palavras e expressões "mudam de sentido segundo as posições sustentadas por aqueles que as empregam, o que quer dizer que elas adquirem seu sentido em referência a essas posições, isto é, em referência às formações ideológicas" (PÊCHEUX, 1997, p. 160).

Entendida a língua, a história e o sujeito em sua opacidade, caberá compreender as SD encontradas no romance $O$ dia em que matei meu pai numa condição de produção específica, a de um relato, de alguém que se encontra preso em uma penitenciária destinada a pessoas com incapacidade mental, ou ainda a de um relato paranoico de alguém que está internado e passa por uma sessão de análise.

Logo, no início do relato, temos a seguinte SD:

(SD1) O dia que matei meu pai era um dia claro, de uma claridade difusa, sem sombras, sem relevos. Ou talvez tenha sido cinzento, daquele cinza que tinge até as almas menos propensas à melancolia. É estranho que esse seja o único detalhe que não me lembre, todos estão ainda bem vívidos dentro de mim. E que importa? A moldura, ela foi só isso - moldura. (SABINO, 2009, p. 9)

Um filho matar um pai demonstra uma FD marcada por uma série de efeitos de sentidos: do pecado, do proibido, da quebra de um valor sagrado, se pensados esses discursos dentro de uma moral social e de uma moral cristã. 
Estamos chamando de Moral Social a todo o discurso que regula a sociedade por uma ordem que remonta o conceito de certo e errado, de bom e mal, de direito e dever que, em última instância, assegura a segurança e a ordem social. O discurso da moral social tem a fundação dos seus sentidos no Discurso da Moral Religiosa. (MALUF-SOUZA, 2000, p. 23)

O assassinato já indica um ato indevido, perante as mais variadas ideologias religiosas, fato destacado nas FD do cristianismo, condizendo a uma prática incabível quando se trata de um assassinato de um pai, o qual atinge situações próprias aos discursos de uma sociedade patriarcal ocidental, cuja instituição familiar é centralizadora de significados. Payer (2005) destaca que na Idade Média a Igreja é quem determinava o que era certo aos indivíduos que deveriam seguir as leis divinas. Esses ideais se efetivam na FD cristã até hoje, embora a legitimação das leis hoje se deva ao Estado. Isto é, na Idade Média, o homem é determinado pelo discurso religioso e, que a partir da Revolução Francesa, as leis próprias ao Estado são as quais tornam indivíduos esses homens, ditos cidadãos. A lei vinculada ao Estado tem o mesmo efeito que o discurso religioso tinha da Idade Média.

Visto como pecado o ato de matar o pai evoca o sentido de rompimento com o sagrado, caindo na ideia de um discurso do profano, aquilo que, dentro do discurso religioso, como nas FD demarcadas na ideologia cristã, é inaceitável se pensadas as condições de um sujeito "mentalmente estável". Na obra humanista de Gil Vicente (1997), O auto da barca do inferno, apenas os cavalheiros das cruzadas e Joanes, o parvo são salvos do inferno, por conta de suas ações. Isto é, o louco pode ser visto no discurso da ignorância, pureza e inocência, caso de Joanes. Mesmo assim, matar o pai, por conta de um estado demente, numa FI cristã, incorre num processo de algo profano.

Consequentemente, podemos dizer que o sentido não existe em si mas é determinado pelas posições ideológicas colocadas em jogo no processo sócio-histórico em que as palavras são produzidas. As palavras mudam de sentido segundo as posições daqueles que as empregam. Elas "tiram" seu sentido dessas posições, isto é, em relação às formações ideológicas nas quais essas posições se inscrevem. (ORLANDI, 2007, p.42-43)

Em épocas cuja lei de sangue imperava, matar o pai era símbolo de fortaleza, num princípio de continuação de horda e legado nas tribos germânicas. Visto tal fato numa perspectiva da FD cristã, o ato tornou-se inaceitável. Logo, em FD distintas, os sentidos se deslocam, dependendo de como o processo sócio-histórico foi constituído. O que era visto como pecado em uma época, necessariamente não o é em outra.

Os efeitos de sentido possíveis no conceito de loucura são grandes exemplos dessa mudança de significados, quando pensadas FI diversas. O louco da contemporaneidade, no mundo ocidental, já foi o herói do passado, quando pensado, por exemplo, épocas como a das Cruzadas. Essa mesma situação no mundo oriental ainda carrega o valor de heróis, pensado o discurso dos radicais islâmicos. Aos olhos do mundo ocidental, esses "radicais" são loucos e na FI de muitas pessoas do mundo oriental, heróis do mais alto valor. 
O discurso religioso, por meio de FD cristã da época das Cruzadas, via no homem que matava infiéis, um herói, não levando em conta se essa pessoa fizesse esse ato com requinte de crueldade, até por que isto não estava colocando em pauta nos efeitos de sentido do discurso da época. Como anteriormente mencionado, na obra Auto da barca do inferno, escrita no final da Idade Média, os cavalheiros das cruzadas foram salvos, mesmo tendo matado muitas pessoas. Se hoje, alguns desses cavalheiros fossem levados ao júri, alguns sofreriam medida de segurança, pois seriam considerados loucos, no nível do discurso científico das FD da medicina e do direito contemporâneos, pois seus atos seriam classificados como desvio perante uma lógica constitutiva de princípios próprios aos processos da alteridade, dos direitos humanos e da dignidade da pessoa humana.

Voltando à SD1, os itens lexicais nos levam a várias veredas analíticas quanto aos efeitos de sentido dessa loucura. O dia claro pode apresentar a imagem de algo explícito ou esclarecedor, 'claro' pode ser o contrário de 'escuro' ou alguma coisa que era impossibilitada de percepção e passa a ter. Matar o pai em um dia claro poderia demonstrar a certeza de tomada de decisão, uma vez que o efeito de sentido tenderia a noção de algo esclarecedor, contudo, a claridade é difusa.

O conceito de difusão, na química, quando se pensa em luz, traz tanto a ideia de reflexo quanto a de transmissão. Essa claridade difusa é o reflexo ou a própria transmissão da luz por meio de um vidro. Matar o pai trouxe essa claridade difusa, de um reflexo de quem matou ou ainda de um processo contínuo, de transmissão, já que é sem sombras e sem relevos.

Quando se pensa em sem sombras, há o efeito de sentido como o de algo que quer indicar a não existência que algo que persegue e sempre está junto, as sobras, nesse caso podendo ser o passado. Ou ainda, um inconsciente demonstrando sua angústia e a sua impossibilidade de apagar marcas do passado. Se há luz, há sombra. Se há luz, é claro. Mas se é claro, não deveria necessariamente, ser difuso. Reforça-se ainda ser sem relevos, o que é demarcado, que se sente por meio do tato, logo se pega. Tem-se a materialização dessas sombras do inconsciente, as quais, numa acepção psicanalítica seriam as luzes desse sujeito assujeitado a sua própria loucura.

Há, nesse primeiro momento, uma FD do discurso da logicidade e racionalidade, que reforça o efeito de sentido do discurso de segurança do ato efetivado, o assassinato do pai, tudo claro, certo e difuso. $\mathrm{O}$ ato de matar o pai tem que ser justificado como algo lógico e racional, em que o uso de palavras como 'claro', dentro dessa FD, demarcam essa racionalidade.

Por FD do discurso da logicidade e da racionalidade, vamos entender um discurso construído num movimento histórico que tem seu início na tradição cartesiana, do cogito, do penso logo existo, num discurso dedutivo, lógico e matemático. Passa pela concepção contratualista do Iluminismo, que reforçou e deu voz a uma subjetividade, demarcada no lema da revolução Francesa: Liberdade, Igualdade e Fraternidade. Alcançando o ápice da racionalização com o método positivista de Comte. Em todos esses momentos, há um sujeito que pensa dominar seus sentidos, em Descartes, só existo porque penso; em Rousseau, eu existo, e isso deve ser levado em conta; em Comte, eu posso construir métodos que objetivam as coisas, o homem no domínio técnico de seus instrumentos. 
O uso de sinonímias para 'claro' dentro dessa FD do discurso da logicidade e da racionalidade efetiva o processo discursivo de reiteração, como argumento de defesa perante o ato de matar o pai. Para Pêcheux (1997, p. 161), o processo discursivo designa "o sistema de relações de substituição, paráfrases, sinonímias, etc., que funcionam entre elementos linguísticos - 'significantes' - em uma formação discursiva dada". Quer dizer que o uso de uma palavra ou da repetição de palavras com significados próximos necessariamente não signifique a mesma coisa, mesmo que estas palavras estejam dentro de uma mesma FD ou pertença à outra. Por exemplo, o 'claro' na FD da loucura pode ser justamente o sombrio, o estado de névoa, sem visibilidade, de tom soturno e na FD da logicidade, o ato certeiro de decisão de assassinato do pai.

A FD do discurso da loucura estaria no discurso contemporâneo baseada num movimento de antítese à FD do discurso da logicidade e racionalidade, uma vez que o louco ao ser visto como diferente deve encarnar caracteres distintos daqueles ditos normais. Várias áreas científicas, em especial, a psicanálise, desconstroem tal ideário. A crítica se dá à psicose vista como meramente uma perda de razão a ser tratada em nível de hospitais psiquiátricos, embora no começo da própria psicanálise esse fato tenha acontecido.

Se o conceito de neurose é parte integrante do vocabulário da psicanálise, o da psicose aparece, a princípio, como um anexo proveniente do saber psiquiátrico e adequado a uma medicina manicomial, pautada numa concepção do sujeito que se organiza em torno da idéia de alienação e perda da razão. (ROUDINESCO; PLON, 1998, p. 621)

A partir, principalmente dos estudos de Freud e Lacan, a psicose deixará de ser vista como uma desrazão e a ser estudada quanto a processos lógicos, isto é, haveria razão na loucura. No discurso moralmente aceito, o louco continua sendo jogado à margem, tanto que o Estado, por meio da medida de segurança, retira o louco do convívio social a fim de garantir a segurança e o bem-estar de todos os outros, os não-loucos, os normais. Essa alienação do sujeito é baseada em termos de exclusão, os laudos que atestam essa 'desrazão', isto é, loucura, compõem-se:

na interpelação histórico-ideológica que os instam a funcionarem inscritos nos sentidos que instituíram a necessidade de instalar a classe médica (psicólogos e psiquiatras) para 'humanizar' a pena para o homem que não pode ser responsabilizado; no silenciamento do crime e na exaltação da loucura como lugar de interdição e de exclusão do convívio e da produtividade - regras ditadas pela sociedade disciplinar $-[\ldots]$. (MALUF-SOUZA, 2000, p. 32)

Em seguida, nessa mesma SD1, tem-se: Ou talvez tenha sido cinzento, daquele cinza que tinge até as almas menos propensas à melancolia. A denominação 'talvez' expressa uma dúvida, a qual tem seu efeito de sentido reforçado por 'cinzento' e 'cinza'. Os efeitos de sentido possibilitados nessa contradição de claro e escuro, e do surgimento de uma relação com o 'cinza' são possíveis principalmente quando pensada a conjuntura do discurso de um homem com demência mental, isto é, de uma FD da loucura. 
O 'cinza' efetiva-se tanto na FD da racionalidade quanto na FD da loucura como um processo de interpelação de interdiscurso no que se refere à discursividade, num processo dual do real da língua e do real da história. 'Cinza' é um já-dito constituindo de referências discursivas de uma cor que demarca tristeza, angústia e até mesmo demência.

O discurso é naturalmente um interdiscurso, pois a forma-sujeito entendida como matriz de sentidos é uma ilusão. Podemos alegar a existência de pré-construídos, como elementos que preenchem argumentos do que já é dito em dada FD. Isto se deve, em especial, ao que se denomina memória discursiva, com a repetição do já-dito. Por isso, o interdiscurso pode ser entendido como a importação de um termo de uma FD e sua tradução metafórica para uma outra FD.

Se pensarmos o interdiscurso do 'cinza' quanto aos deslizamentos de efeitos de sentidos, podemos tomá-lo em relação à cor branca e a cor preta. O branco é o começo, preto é o fim e cinza é o meio indefinido, nem uma coisa nem outra, dissolução de certezas. Cinza é tido como a ausência de sentimentos. Cor do tédio, do antiquado e da crueldade.

Para Chavalier e Gheerbrant (1986), o branco e o negro são cores absolutas e marcadas em sua contrariedade. Nos sentidos, estabelecem-se nas relações de dia e noite, nascimento e morte, indicando passagens nos rituais das diversas culturas. A cor preta se constitui na ideia do caos original de uma gênese universal e o branco como um silêncio constitutivo de um espaço não vazio.

Na natureza, o tempo nublado é cinzento. Na SD1, o cinzento, cinza está ligado à melancolia, fato de reforço de um interdiscurso baseado na tristeza profunda, melancólica ou de algo que não está totalmente claro. Tanto numa FD do discurso racionalizante quanto na do discurso da loucura, esse efeito é demarcado no funcionamento da discursividade, numa FD racionalizante pode ser a tristeza em si e, na FD da loucura, o deslize para aquilo que não se vê.

Nessa perspectiva, o interdiscurso, longe de ser efeito integrador da discursividade torna-se desde então seu princípio de funcionamento: é porque os elementos da sequência textual, funcionando em uma formação discursiva dada, podem ser importados (meta-forizados) de uma sequência pertencente a uma outra formação discursiva que as referências discursivas podem se construir e deslocar historicamente. (PÊCHEUX, 2012, p. 158)

O 'cinza' é tomado em seu efeito metafórico, é entendido como uma cor sem força, pois o branco entendido como sublime está sujo, manchado e o preto perde sua aura de força e toma sentido de enfraquecimento. $\mathrm{O}$ 'cinza' é considerado débil para ser masculino e ameaçador para ser feminino, não é quente nem frio, não é nem material nem metal, carregando um estado de vacância, considerado por isso uma cor sem caráter (HELLER, 2013).

Nesse sentido, o contexto em que o interdiscurso do 'cinza' como algo vago reforça os efeitos de sentido da FD do discurso da loucura, pois mesmo que a formasujeito entenda explicar a lógica de seu ato, é na FD da loucura que os sentidos de assujeitamento discursivo desse sujeito aparece ganhar força. Pois, mesmo sendo 
considerado louco, traz suas argumentações dentro de uma lógica pautada num discurso cartesiano, próprio de sua FD do discurso de logicidade. "Ou seja, os "contextos" fazem parte de uma história, já que, também nessas instâncias de enunciação, os enunciadores se assujeitam à sua FD” (POSSENTI, 2005, p. 369).

Tudo era 'claro' e agora está 'cinza', uma cor indefinida, nem branco nem preto, sem vida, sem cor, nem claro nem mesmo escuro. Mas é um 'cinza' que tinge, isto é, mais do que pintar, ele tinge. As metáforas 'pintar a alma' e 'tingir a alma' direcionam para o efeito de sentido de força dessa melancolia perante as decisões tomadas na descrição do relato, no caso, o assassinato do pai. Destaca-se, que a partir da escolha da expressão tingir ao invés de pintar, a ideia é de algo sem volta, a alma tingida é a marcada sem chance de retornar para a cor original.

Tem-se nessa relação pintar e tingir o que é denominado por efeito metafórico, em que uma palavra no lugar de outra num contexto dado promove o deslizamento de sentido, o qual se dá pelo processo de construção social e histórica de dado momento, num processo de analogia próprio ao interdiscurso. "Mais claramente: o (efeito de) sentido nunca é o sentido de uma palavra, mas de uma família de palavras que estão em relação metafórica (ou: o sentido de uma palavra é um conjunto de outras palavras que mantêm com ela uma certa relação)" (POSSENTI, 2005, p. 372).

A claridade passa a dar espaço ao difuso como uma névoa, a claridade difusa poderia ser como a de água em evaporação, em que se pode ver, mas que a própria claridade prejudica o alcance dessa visão. Vemos que a FD do discurso da logicidade vai dando contornos a uma FD do discurso da loucura. Contudo, precisamos reforçar o argumento de que não podemos esquecer que pensadas as condições de produção desse discurso, temos um homem considerado demente, logo sua FD estaria embasada num discurso da loucura.

Como os sentidos lhe fogem ao seu domínio, a claridade difusa, tingida de cinza alude a uma certeza que apresenta inconstâncias. E termina seu raciocínio do seguinte modo: É estranho que esse seja o único detalhe que não me lembre, todos estão ainda bem vívidos dentro de mim. E que importa? A moldura, ela foi só isso - moldura. No início, tudo era claro, contudo agora, paira a dúvida de como se estabeleceu o que ele chama de moldura, isto é, o cenário do crime. Reforça-se que todos os outros detalhes estejam vívidos na memória, e que a moldura não importaria. Mas a SD1 teve início nos efeitos de sentido próprios ao que é claro ou ainda esclarecedor.

Os efeitos de sentido de moldura devem ser pensados, pois podem representar a ideia de condicionamento social, de um indivíduo pré-existente à sociedade, sem poder de modificar o seu entorno, muito menos os que pertencem a essa ambientação social. Isto é, matar o pai pode evocar o sentido de fuga de uma realidade que não condiz aos seus anseios.

Moldura está ligada à noção de molde, num discurso da loucura, matar o pai era destituir-se de um molde que fora negado à vida toda por meio de argumentos discursivamente localizados em interdiscursos de uma FD da logicidade. Esse jogo de processos discursivos entre a racionalidade e a loucura acontecerá de modo constante no relato desse sujeito que descreve ter matado o pai. 
Podemos pensar esses discursos interpelando esse sujeito, de modo que a interpelação ideológica, a influência e determinações das formas de poder, fundadas nas composições e das instituições sociais estarão demarcadas nos efeitos de sentidos possibilitados, principalmente, nos efeitos de sentido condizentes à figura paterna. "Toda formação discursiva dissimula, pela transparência do sentido que nela se constitui, sua dependência com respeito ao 'todo complexo com dominante' das formações discursivas, intrincado no complexo das formações ideológicas” (PÊCHEUX, 1997, p. 162).

Essa FD do efeito de sentido do 'claro' como matriz de uma certeza é constituída numa FD do discurso racionalista, de um sujeito que tem domínio sobre seus atos, mesmo que a atitude por ele tomada, a de matar o pai, seja questionada dentro da lógica constitutiva do discurso científico tanto de FD do direito quanto da medicina.

\section{CONSIDERAÇÕES FINAIS}

Pode-se perceber a partir desse trabalho, com a análise da SD delineada que mesmo o texto literário, marcado pela suposta 'subjetividade', pode ser visto quanto suas condições de produção e efeito de sentido. Tomar um corpus para exemplificar essa possibilidade analítica destaca como a $\mathrm{AD}$ pode estabelecer diálogos com áreas artísticas, principalmente, ao destituirmos valores subjetivos como o da autoria, pensando o texto como um acontecimento discursivo.

Destarte, textos não tão usuais à $\mathrm{AD}$, como a produção literária, podem ser pensados em sua materialidade linguística, entendidos em seus níveis discursivos com efeitos de sentidos interpelado por ideologias e o inconsciente. A AD muito avança na atualidade quando promove novas interfaces e possibilidades analíticas, vide os estudos dos discursos das cidades, da voz e de produções artísticas.

É importante não perder de foco os conceitos basilares da AD da linha francesa, em que intenção e domínio sobre os sentidos não se perfazem, já que somos interpelados o tempo todo em nossa condição de sujeitos assujeitados. Não somos donos do sentido, muito menos, donos do que pensamos, constituímo-nos nesse movimento de atravessamentos ideológicos, da linguagem e do inconsciente. De tal modo que a arte, por ser um produto de processos sociais, sofre interpelações e alienamentos constantes quando as pensamos em seu nível discursivo.

\section{REFERÊNCIAS}

BRANDÃO, Helena Hathsue Nagamine. Análise do discurso: um itinerário histórico. Em: PEREIRA, H.B.C.; ATIK, M.L.G. (Orgs.) Língua, literatura e cultura em diálogo. São Paulo: Ed. Mackenzie, 2003. Disponível em: http://www.fflch.usp.br/dlcv/lport/pdf/brand005.pdf. Acesso em: 02 de jan. 2015.

CHEVALIER, Jean; GHEERBRANT, Alain. Diccionario de los símbolos. Barcelona: Editorial Herder, 1986. 
FERNANDES, C.A. Análise do discurso da literatura: rios turvos de margens indefinidas. Em: FERNANDES, C.A.; GAMA-KHALIL, M.M.; JUNIOR, J.A.A. (Orgs.). Análise do discurso da literatura: rios turvos de margens indefinidas. São Carlos: Claraluz, 2009. pp. 08-25.

FINK, B. O sujeito lacaniano: entre a linguagem e o gozo. Rio de Janeiro: Zahar, 1998.

HELLER, Eva. A psicologia das cores: como as cores afetam a emoção e a razão. São Paulo: Gustavo Gili, 2013.

MALDIDIER, Denise. A inquietação do discurso: (re)ler Michel Pêcheux hoje. Trad. Bras. Campinas: Pontes, 2003.

MALUF-SOUZA, Olimpia. As condições de produção dos laudos periciais de indivíduos com suspeição de insanidade mental. Dissertação. Mestrado em Linguística. Campinas, DL/IEL/UNICAMP, 2000.

MAZIÈRE, Francine. A análise do discurso: história e práticas. Trad. Bras. São Paulo: Parábola Editorial, 2007.

ORLANDI, E.P. Análise do discurso: princípios e procedimentos. $7^{\mathrm{a}}$. ed. Campinas: Pontes, 2007.

. Cidade dos sentidos. Campinas: Pontes, 2004.

Língua e conhecimento linguístico: por uma história das ideias no Brasil. São Paulo: Cortez, 2002.

PAYER, M.O. Linguagem e sociedade contemporânea - sujeito, mídia, mercado. Rua [Revista do Núcleo de Desenvolvimento da Criatividade da Unicamp - Nudecri], Campinas, n. 11, 9-25, mar., 2005.

PÊCHEUX, Michel. Metáfora e interdiscurso. Em: PÊCHEUX, M. Análise de discurso: Michel Pêcheux. $3^{\mathrm{a}}$. ed. Campinas: Pontes, 2012. 2008

O discurso: estrutura ou acontecimento. Trad. Bras. 5a. ed. São Paulo: Pontes,

Semântica e discurso: uma crítica à afirmação do óbvio. $3^{\mathrm{a}}$. ed. Campinas: Editora da Unicamp, 1997.

Análise automática do discurso (AAD-69). Em: GADET, Françoise; HAK, Tony (Orgs.). Por uma análise automática do discurso: uma introdução à obra de Michel Pêcheux. Trad. Bras. 2a . ed. Campinas: Editora da Unicamp, 1993.

POSSENTI, Sírio. Questões para analistas do discurso. São Paulo: Parábola, 2009. 
Introdução à linguística: fundamentos epistemológicos. Em: MUSSALIM, F; BENTES, A.C. Introdução à linguística: fundamentos epistemológicos. v. 3. $2^{\mathrm{a}}$.ed. São Paulo: Cortez, 2005.

ROUDINESCO, E.; PLON, M. Dicionário de psicanálise. Rio de Janeiro: Zahar, 1998.

SABINO, Mario. O dia em que matei meu pai. Rio de Janeiro: BestBolso, 2009.

SAUSSURE, F. de. Curso de Linguística Geral. 27ª ed. São Paulo: Cultrix, 2006.

VICENTE, Gil. Auto da barca do inferno. São Paulo: FTD, 1997.

Artigo recebido em: junho de 2017.

Aprovado e revisado em: dezembro de 2017.

Publicado em: maio de 2018.

Para citar este texto:

VERSA, Cezar Roberto; SOARES, Alexandre Sebastião Ferrari. Análise do Discurso e Literatura: um diálogo possível no romance $O$ dia em que matei meu pai, de Mario Sabino. Entremeios [Revista de Estudos do Discurso, ISSN 2179-3514, on-line, www.entremeios.inf.br], Seção Temática [Discurso, arte e literatura - Parte I], Programa de Pós-Graduação em Ciências da Linguagem (PPGCL), Universidade do Vale do Sapucaí (UNIVÁS), Pouso Alegre (MG), vol. 16, p. 259-273, jan. - jun. 2018. DOI: http://dx.doi.org/10.20337/ISSN2179-3514revistaENTREMEIOSvol16pagina259a273 